\title{
Descemet's Membrane Endothelial Keratoplasty (DMEK)—Why Surgeons Should Consider Adopting Endothelium-in Techniques
}

\author{
Hon Shing Ong ${ }^{1,2,3}$ and Jodhbir S Mehta',2,3,4 \\ 1. Corneal and External Diseases Department, Singapore National Eye Centre, Singapore; 2. Tissue Engineering and Stem Cell Group, \\ Singapore Eye Research Institute, Singapore; 3. Duke-National University Singapore Graduate Medical School, Singapore; 4. School of Material \\ science and Engineering, Nanyang Technological University, Singapore
}

DOI: https://doi.org/10.17925/USOR.2019.12.2.65

$\mathrm{V}$ isual loss from corneal endothelial failure is a leading indication for corneal transplantation. The two main transplantation techniques to treat corneal endothelial failure are Descemet's stripping automated endothelial keratoplasty (DSAEK) and Descemet's membrane endothelial keratoplasty (DMEK). DSAEK can achieve predictable visual outcomes and improved graft survival compared to traditional full-thickness penetrating keratoplasties. Thus, DSAEK has been widely adopted by surgeons. DMEK, where only Descemet's membrane and its endothelium is harvested, is the more recent advancement. Compared to DSAEK, DMEK has been shown to achieve faster visual recovery, better visual outcomes, and lower rejection risk. However, many surgeons are slow to adopt DMEK for treating endothelial diseases. This is attributed to the challenges in surgical technique and higher risks of complications, notably, graft detachments and iatrogenic graft failures. The vast majority of techniques used in published studies are "endothelium-out" techniques, where DMEK grafts are loaded and inserted such that the endothelium remains on the outside. These techniques involve injection of the DMEK scroll into the anterior chamber, leaving the surgeon to unfold the free-floating graft within the eye which can be technically difficult. More recently, endothelium-in techniques for graft insertion, has been described. It has been introduced to make DMEK surgery easier and more predictable by maintaining graft orientation during insertion. Current evidence suggests that the outcomes of "endothelium-in" techniques are comparable to those of endothelium-out techniques. Given the advantages of endothelium-in techniques, corneal surgeons may wish to adopt such techniques, especially when performing transplants in eyes with complex anterior segments.

\section{Keywords}

Corneal transplantation, corneal endothelial failure, Descemet's membrane endothelial keratoplasty (DMEK), endotheliumin technique, corneal surgery

Disclosure: Jodhbir Mehta holds a patent on the EndoGlide and receive royalties. Hon Shing Ong has nothing to declare in relation to this article.

Review Process: Double-blind peer review.

Compliance with Ethics: This study involves a review of the literature and did not involve any studies with human or animal subjects performed by any of the authors.

Authorship: The named authors meet the International Committee of Medical Journal Editors (ICMJE) criteria for authorship of this manuscript, take responsibility for the integrity of the work as a whole, and have given final approval for the version to be published.

Received: July 11, 2019

Accepted: October 14, 2019

Citation: US Ophthalmic Review. 2019;12(2):65-8

Corresponding Author: Hon Shing Ong, Singapore National Eye Centre, 11 Third Hospital Avenue,

singapore 168751. E: honshing@gmail.com

Support: No funding was received in

the publication of this article.
The health of the corneal endothelium, the innermost single cell layer of the cornea, is essential in maintaining corneal transparency. This is achieved through a passive diffusion of fluid across leaky inter-cellular tight junctions from the aqueous humor into the corneal stroma and active ionic pumps, which moves fluid against an osmotic gradient from the corneal stroma back into the aqueous humour. ${ }^{1-4}$ This "pump-leak" mechanism maintains the corneal aqueous content at an ideal level of $78 \%$. This supports optimal inter-lamellar spacing of collagen fibrils within the corneal stroma to achieve corneal transparency. ${ }^{5,6}$

An accelerated loss of corneal endothelial cells occurs in diseases of the corneal endothelium, such as Fuchs' endothelial corneal dystrophy or ocular insults including intraocular surgeries, anterior segment laser treatments, ocular trauma or inflammation. When the corneal endothelial cell density falls below a certain threshold, the ability of the corneal endothelium to regulate corneal hydration becomes impaired. ${ }^{7-9}$ In corneal endothelial failure, the cornea becomes edematous, resulting in a loss in its transparency and eventual visual impairment.

Visual impairment from corneal endothelial failure is a leading indication for corneal transplantation. 10,11 Over the past two decades, there has been a fundamental shift in the treatment of corneal diseases towards replacing only diseased parts of the cornea. ${ }^{12,13}$ Indeed, the concept of selective replacement of damaged endothelial cells has revolutionized the treatment of corneal endothelial failure. ${ }^{13}$ Such corneal transplantation techniques, known as endothelial keratoplasties (EKS), are able to achieve improved visual outcomes, lower risks of graft rejection, and superior graft survival rates, compared to traditional full-thickness penetrating keratoplasties (PKS). ${ }^{14,15}$ As these EK techniques are minimally invasive, they avoid full-thickness central corneal trephination and intraoperative 'open-sky' situations, thereby reducing the risk of sight-threatening complications like expulsive hemorrhage. They also offer better mechanical integrity and overall globe strength. EKs have thus replaced PKs as the standard of care for treating corneal endothelial failure. 10,11,16 
In current clinical practice, there are two leading EK techniques: Descemet's stripping automated endothelial keratoplasty (DSAEK) and Descemet's membrane endothelial keratoplasty (DMEK). In DSAEK, transplanted donor endothelial grafts consist of donor endothelium, Descemet's membrane, and some posterior stroma. Since its introduction, much research has been focused on methods to improve the post-operative outcomes of DSAEK surgical technique. Advancements such as the development of devices for graft insertion have greatly simplified DSAEK. ${ }^{17}$ These devices include the Busin Spatula (Moria Ophthalmic Instruments, Antony, France), ${ }^{18}$ the DMEK EndoGlide ${ }^{T M}$ (Network Medical Products, Rippon, UK), ${ }^{19}$ and the EndoSaver ${ }^{\circledR}$ (Ocular Systems Inc, Winston Salem, NC, USA), amongst various others. Such devices maintain graft orientation during graft insertion and are less traumatic to the endothelium as they minimize the need for intraocular manipulation when unfolding the graft. ${ }^{17}$ With predictable visual outcomes and improved graft survival compared to PK, DSAEK has been widely adopted by corneal surgeons. ${ }^{11}$

DMEK is the more recent advancement in EK surgery. In DMEK, only the Descemet's membrane with its endothelium is harvested from donor tissue and is transferred into the recipient's eye. By only replacing tissues affected by endothelial diseases, DMEK is anatomically more accurate. Indeed, DMEK has been shown to achieve more rapid visual recovery and better visual outcomes compared to DSAEK.20-23 Unlike DSAEK, as stromal tissue is not transplanted in DMEK, a change in corneal profile is avoided in the latter. DMEK is thus associated with improved refractive outcomes. ${ }^{21}$ Recent studies comparing DMEK and DSAEK have also reported lower endothelial rejection rates in DMEK. ${ }^{24}$

Despite the advantages of DMEK over DSAEK, many corneal surgeons have been slow to adopt DMEK as the main procedure to treat endothelial failure. $^{12}$ According to the Eye Bank Association of America (2018 Eye Banking Statistical Report-page 6), DSAEK still accounts for over $60 \%$ of EK procedures performed in the United States. ${ }^{11}$ This has been attributed to the challenges in surgical techniques and the associated increased early post-operative complications, notably graft detachments and iatrogenic graft failures due to inadvertent 'inverted ' grafts.

\section{Endothelium-out DMEK techniques}

Current techniques of transferring the DMEK graft into the anterior chamber involve the insertion of the graft through a small corneal incision. In 'endothelium-out' techniques, the DMEK graft is loaded and inserted such that its endothelium remains on its outer surface (Figure 1). The first DMEK, introduced by Melles, was an endothelium-out technique, ${ }^{25}$ and there have been various modifications to this technique since. Thus, the vast majority of techniques used in published studies are endotheliumout techniques. ${ }^{22,26-37}$

To protect the Descemet's membrane scroll from the surgical wound, different instruments have been designed for DMEK graft insertion. These include glass injector ${ }^{38,39}$ and intraocular lens cartridges. ${ }^{40,41}$ Nevertheless, being endothelium-out, the DMEK graft is still potentially susceptible to endothelial cell loss caused by contact of its endothelium with the lumen of the insertion device. Furthermore, endothelium-out techniques all involve the injection of the scroll of DMEK graft into the anterior chamber in its entirety, leaving the surgeon to unscroll the free-floating graft within the eye.
Figure 1: An example of an "endothelium-out" surgical technique of Descemet's membrane endothelial keratoplasty
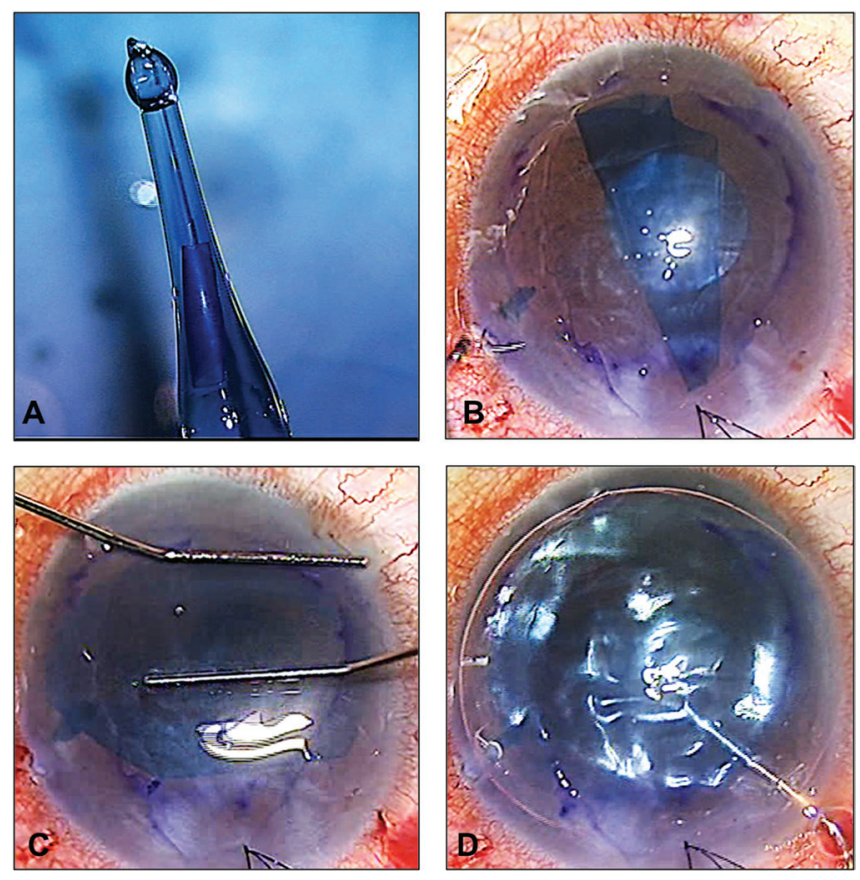

A. Scrolled DMEK graft with endothelium on its outer surface stained with Membrane Blue Dual ${ }^{\circledR}$ (D.O.R.C. The Netherlands) and loaded into a glass injector (Geuder AG, Heidelberg, Germany); B. Free-floating DMEK graft injected into the anterior chamber $C$. Unfolding of the Descemet's membrane graft by tapping on the recipient's corneal surface; D. Gas bubble injected into anterior chamber to provide tamponade of the DMEK graft

DMEK = Descemet's membrane endothelial keratoplasty.

The unscrolling of a free-floating DMEK graft, after its intraocular insertion, is considered the most difficult step in DMEK. It can be challenging, unpredictable, and time consuming. ${ }^{42}$ The challenge comes from the fact that the Descemet's membrane, once separated from the stroma, has a natural tendency to form a scroll with its endothelium on its outer surface. The scroll can be tight, especially for tissues harvested from younger donors. Compared to DSAEK, different surgical skills with steeper learning curve are required by the surgeon. ${ }^{43}$ The surgeon must learn various techniques to unfold a free-floating DMEK graft within the anterior chamber (Figure 1). ${ }^{44-46}$ Such techniques include methodological approaches to unfolding a doublescrolled graft by tapping the cornea in a shallow anterior chamber, the use of intracameral water currents to shift and orientate the graft and air bubbles to assist in tight or single scrolls. ${ }^{45,46}$ As endothelium-out techniques are reliant on such water currents and air bubbles in graft unscrolling, surgery can be difficult in eyes with abnormal anterior segments (e.g., iris defects). In cases such as tight graft scrolls or a very deep anterior chamber, the unfolding of the graft can also be technically challenging. ${ }^{47}$

\section{Endothelium-in DMEK techniques}

The concept of "endothelium-in" graft insertion techniques for DMEK surgery has recently been introduced (Figure 2). ${ }^{48-51}$ After harvesting, the DMEK graft is folded, often in a tri-fold, with its endothelium on its inner surface. This prevents the graft from naturally scrolling with its endothelium on the outer surface. Such endothelium-in techniques are thought to 
Figure 2: An example of an "endothelium-in" surgical technique of Descemet's membrane endothelial keratoplasty using the DMEK EndoGlide

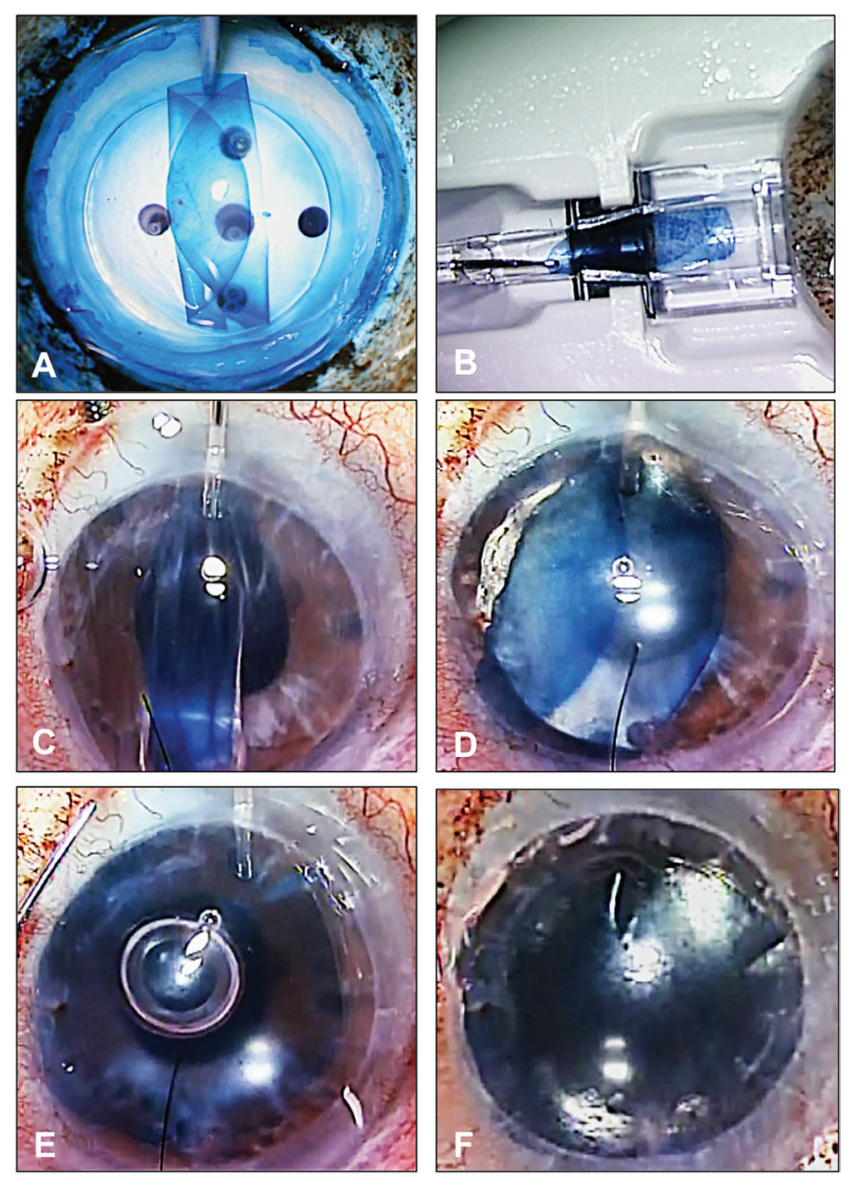

A. Endothelium of DMEK graft is folded into a tri-fold with its endothelium in its inner surface; B. DMEK graft is pulled and loaded into the DMEK EndoGlide TM (Network Medical Products, Rippon, UK); C. Graft is pulled into the anterior chamber with microforceps with its endothelium facing down; $D$. Graft starting to unfold with its orientation maintained; E. Full unfolding of the graft with its orientation maintained whilst graft is still being held with microforceps; F. Full air-gas tamponade of graft.

DMEK = Descemet's membrane endothelial keratoplasty.

have the advantage of minimizing endothelial cell loss from trauma of the endothelial cells on the luminal walls of insertion devices. Furthermore, in endothelium-in techniques, the donor tissue is inserted into the eye in the correct orientation with the endothelium facing downwards. Following insertion in an endothelium-in configuration, the DMEK graft starts to unfold to adopt its natural endothelium-out scroll, essentially "assisting" the surgeon in graft unfolding. Moreover, endothelium-out techniques use water currents and air bubbles in the anterior chamber to orientate and unscroll the free-floating graft and thus surgical complexity is dependent on anterior segment anatomy. Such reliance on a normal anterior segment (e.g., intact iris diaphragm) is circumvented in endothelium-in techniques. These features of endothelium-in techniques thus minimize the surgical challenges of graft orientation and unfolding of a free-floating scrolled graft within the eye, making surgery more controlled and predictable.
Endothelium-in techniques can be inserted into the eyes by a) direct injection into the anterior chamber or b) pulled into the eye using various pull-through devices or intraocular lens cartridges. In eyes with normal anatomies, endothelium-in techniques provide unfolding advantages as described above, whether the graft is injected or pulled into the eye. In eyes with abnormal anatomies (e.g., iris defects, previous vitrectomies, aphakia), pull-through methods have tremendous advantages. Furthermore, various pull-through devices have been designed to mimic DSAEK procedures, which are familiar to many corneal surgeons. ${ }^{48}$

\section{Outcomes of endothelium-out and endothelium-in techniques}

\section{Endothelium-out techniques}

In current literature, the vast majority of published studies on DMEK are based on endothelium-out techniques. $22,26-3,5,52$ Studies published are mainly retrospective case control studies or case series.52 At 6 months, $42.5-75.0 \%$ of cases have been reported to achieve a best-corrected visual acuity (BCVA) of 20/25 or better, and 17-44\% have been reported achieve a BCVA of 20/20 or better..$^{52}$ Mean endothelial cell losses have ranged from 19-53\% amongst various studies with a mean time point of 12 months.52 For graft complications, re-bubbling rates, primary graft failure rates, secondary graft failure rates, and graft rejection rates ranged from $0.0-82.0 \%, 0.0-18.2 \%$, $0.0-7.0 \%$, and $0.0-7.0 \%$ respectively. ${ }^{.2}$

\section{Endothelium-in techniques}

We found only three studies in the literature that used endotheliumin techniques, all of which were retrospective studies. ${ }^{48-50,52}$ In one study, $66.7 \%$ of cases achieved BCVA of 20/25 or better at 3 months. ${ }^{48}$ The mean endothelial cell loss ranged from $29.5-56.0 \%$ (two studies) with a mean time point of 12 months. ${ }^{4849}$ Reporting on complications, graft detachment re-bubbling rates and primary graft failure rates ranged from 10.0-34.1\% (three studies) ${ }^{48-50}$ and $0.0-3.0 \%$ (two studies), ${ }^{48.49}$ respectively.

One recent case control study of 754 cases compared endothelium-out to endothelium-in DMEK graft insertion techniques. ${ }^{51}$ No significant differences in endothelial cell loss, rates of re-bubbling for graft detachments, and primary graft failure rates were found between the two techniques. Various laboratory studies have reported no significant differences in endothelial cell loss when DMEK grafts were loaded endothelium-in and pulled-through or loaded endothelium-out and injected-through different graft insertion devices. ${ }^{53-55}$ However, pre-clinical laboratory studies have also reported significantly shorter graft unfolding times for endothelium-in compared to endothelium-out techniques..$^{55}$

\section{Conclusion}

Despite the small number of studies reporting on endothelium-in techniques, current evidence suggests that the outcomes of these techniques are comparable to outcomes of endothelium-out techniques. With the intra-operative challenges of unscrolling a free-floating DMEK graft encountered in endothelium-out techniques, corneal surgeons may wish to consider adopting endothelium-in DMEK techniques. This is especially the case in more challenging eyes with complex anterior segments (e.g., aphakia, large iris defects, vitrectomized eyes, previous glaucoma filtration surgery), where many surgeons still prefer DSAEK in these situations. $\square$ 
1. Srinivas SP. Dynamic regulation of barrier integrity of the corneal endothelium. Optom Vis Sci. 2010;87:E239-54.

2. Carlson KH, Bourne WM, McLaren JW, Brubaker RF. Variations in human corneal endothelial cell morphology and permeability to fluorescein with age. Exp Eye Res. 1988;47:27-41.

3. Maurice DM. The location of the fluid pump in the cornea. J Physiol. 1972;221:43-54.

4. Bourne WM. Clinical estimation of corneal endothelia pump function. Trans Am Ophthalmol Soc. 1998;96:229-39; discussion 239-42.

5. Bonanno JA. Molecular mechanisms underlying the cornea endothelial pump. Exp Eye Res. 2012;95:2-7.

6. Edelhauser HF. The balance between corneal transparency and edema: the Proctor Lecture Invest Ophthalmol Vis Sci. 2006;47:1754-67.

7. Tuft SJ, Coster DJ. The corneal endothelium. Eye. 1990;4:389-424.

8. McCartney MD, Wood TO, MCLaughlin BJ. Freeze-fracture label of functional and dysfunctional human corneal endothelium. Curr Eye Res. 1987;6:589-97.

9. Mahdy MA, Eid MZ, Mohammed MA, et al. Relationship between endothelial cell loss and microcoaxial phacoemulsification parameters in noncomplicated cataract surgery. Clin Ophthalmol. 2012;6:503-10.

10. KA Williams, MC Keane, NE Coffey, et al. Australian Corneal Graft Registry. The Australian Graft Registry 2018 Report. 2018. Available at: https://dspace.flinders.edu.au/xmlui/ bitstream/handle/2328/37917/ACGR\%202018\%20Report. pdf? sequence=3\&isAllowed=y (accessed May 9, 2019).

11. EBAA. Eye Banking Statistical Report. 2018. https://restoresight. org/what-we-do/publications/statistical-report/ (accessed September 18, 2019).

12. Park CY, Lee JK, Gore PK, et al. Keratoplasty in the United States: A 10-Year Review from 2005 through 2014. Ophthalmology. 2015;122:2432-42.

13. Tan DT, Dart JK, Holland EJ, Kinoshita S. Corneal transplantation. Lancet. 2012;379:1749-61.

14. Koenig SB, Covert DJ, Dupps WJ, Jr, Meisler DM. Visual acuity, refractive error, and endothelial cell density six months after Descemet Stripping and automated endothelial keratoplasty (DSAEK). Cornea. 2007;26:670-4

15. Ang M, Soh $Y$, Htoon HM, et al. Five-year graft survival comparing Descemet stripping automated endothelial keratoplasty and penetrating keratoplasty. Ophthalmology. 2016;123:1646-52

16. Guell IL, El Husseiny MA, Manero F, et al. Historical review and update of surgical treatment for corneal endothelial diseases. Ophthalmol Ther. 2014;3:1-15.

17. Ang M, Saroj L, Htoon HM, et al. Comparison of a donor insertion device to sheets glide in Descemet stripping endothelial keratoplasty: 3-year outcomes. Am J Ophthalmol. 2014;157:1163-9.

18. Busin M, Bhatt PR, Scorcia V. A modified technique for desceme membrane stripping automated endothelial keratoplasty to minimize endothelial cell loss. Arch Ophthalmol. 2008;126:1133-7.

19. Khor WB, Mehta JS, Tan DT. Descemet stripping automated endothelial keratoplasty with a graft insertion device: surgical technique and early clinical results. Am J Ophthalmol. 2011;151:223-32.

20. Singh A, Zarei-Ghanavati M, Avadhanam V, Liu C. Systematic review and meta-analysis of clinical outcomes of Desceme membrane endothelial keratoplasty versus Descemet stripping endothelial keratoplasty/Descemet stripping automated endothelial keratoplasty. Cornea. 2017;36:1437-43.

21. Droutsas K, Lazaridis A, Papaconstantinou D, et al. Visual outcomes after Descemet membrane endothelial keratoplasty versus Descemet stripping automated endothelial keratoplastycomparison of specific

22. Tourtas T, Laaser K, Bachmann BO, et al. Descemet membrane endothelial keratoplasty versus descemet stripping automated endothelial keratoplasty. Am J Ophthalmol. 2012;153:1082-90.

23. Guerra FP, Anshu A, Price MO, Price FW. Endothelial keratoplasty: fellow eyes comparison of Descemet stripping automated endothelial keratoplasty and Descemet membrane endothelial keratoplasty. Cornea. 2011;30:1382-6.

24. Marques RE, Guerra PS, Sousa DC, et al. DMEK versus DSAEK for Fuchs' endothelial dystrophy: A meta-analysis. Eur J Ophthalmol. 2019:29:15-22.

25. Melles GR, Ong TS, Ververs B, van der Wees J. Descemet membrane endothelial keratoplasty (DMEK). Cornea. 2006;25:987-90.

26. Monnereau C, Quilendrino R, Dapena I, et al. Multicenter study of Descemet membrane endothelial keratoplasty: first case series of 18 surgeons. JAMA Ophthalmol. 2014:132:1192-8.

27. Ham L, Dapena I, Liarakos VS, et al. Midterm Results of Descemet membrane endothelial keratoplasty: 4 to 7 years clinical outcome Am J Ophthalmol. 2016:171:113-21.

28. Price MO, Feng MT, Scanameo A, Price FW, Jr. Loteprednol etabonate $0.5 \%$ gel Vs. prednisolone acetate $1 \%$ solution after Descemet membrane endothelial keratoplasty: prospective randomized trial. Cornea. 2015;34:853-8.

29. Santander-Garcia D, Peraza-Nieves J, Muller TM, et al. Influence of intraoperative air tamponade time on graft adherence in Descemet membrane endothelial keratoplasty cornea. 2019;38:166-72.

30. Feng MT, Burkhart ZN, Price FW, Jr, Price MO. Effect of donor preparation-to-use times on Descemet membrane endothelia keratoplasty outcomes. Cornea. 2013;32:1080-2.

31. Chaurasia S, Price FW, Jr, Gunderson L, Price MO. Descemet's membrane endothelial keratoplasty: clinical results of single versus triple procedures (combined with cataract surgery). Ophthalmology. 2014;121:454-8.

32. Veldman PB, Dye PK, Holiman JD, et al. The S-stamp in Descemet membrane endothelial keratoplasty safely eliminates upsidedown graft implantation. Ophthalmology. 2016;123:161-4.

33. Heinzelmann S, Bohringer D, Eberwein P, et al. Outcomes of Descemet membrane endothelial keratoplasty, Descemet stripping automated endothelial keratoplasty and penetrating keratoplasty from a single centre study. Graefes Arch Clin Exp Ophthalmol. 2016:254:515-22.

34. Gundlach E, Maier AK, Tsangaridou MA, et al. DMEK in phakic eyes: targeted therapy or highway to cataract surgery? Graefe Arch Clin Exp Ophthalmol. 2015;253:909-14.

35. Gorovoy MS. DMEK complications. Cornea. 2014;33:101-4.

36. Kurji KH, Cheung AY, Eslani $M$, et al. Comparison of visual acuity outcomes between nanothin Descemet stripping automated endothelial keratoplasty and Descemet membrane endothelial keratoplasty. Cornea. 2018;37:1226-31.

37. Regnier M, Auxenfans $C$, Maucort-Boulch D, et al. Eye bank prepared versus surgeon cut endothelial graft tissue for Descemet membrane endothelial keratoplasty: An observationa study. Medicine. 2017;96:e6885.
38. Dapena I, Moutsouris K, Droutsas K, et al. Standardized "no-touch" technique for descemet membrane endothelial keratoplasty. Arch Ophthalmol. 2011;129:88-94.

39. Arnalich-Montiel F, Munoz-Negrete FJ, De Miguel MP. Double port injector device to reduce endothelial damage in DMEK. Eye. 2014:28:748-51.

40. Kruse FE, Laaser K, Cursiefen C, et al. A stepwise approach to donor preparation and insertion increases safety and outcome of Descemet membrane endothelial keratoplasty. Cornea. 2011;30:580-7.

41. Kim EC, Bonfadini G, Todd L, et al. Simple, inexpensive, and effective injector for descemet membrane endothelial keratoplasty. Cornea. 2014;33:649-52

42. Maier AK, Gundlach E, Schroeter J, et al. Influence of the difficulty of graft unfolding and attachment on the outcome in Descemet membrane endothelial keratoplasty. Graefes Arch Clin Exp Ophthalmol. 2015;253:895-900.

43. Phillips PM, Phillips ப, Muthappan V, et al. Experienced DSAEK surgeon's transition to DMEK: outcomes comparing the last 100 DSAEK surgeries with the first 100 DMEK surgeries exclusively using previously published techniques. Cornea. 2017;36:275-9.

44. Ang M, Wilkins MR, Mehta JS, Tan D. Descemet membrane endothelial keratoplasty. Br J Ophthalmol. 2016:100:15-21.

45. Liarakos VS, Dapena I, Ham L, et al. Intraocular graft unfolding techniques in descemet membrane endothelial keratoplasty. JAMA Ophthalmol. 2013;131:29-35.

46. Yoeruek E, Bayyoud T, Hofmann J, Bartz-Schmidt KU. Novel maneuver facilitating Descemet membrane unfolding in the anterior chamber. Cornea. 2013;32:370-3

47. Heinzelmann S, Bohringer D, Haverkamp C, et al. Influence of postoperative intraocular pressure on graft detachment after Descemet membrane endothelial keratoplasty. Cornea. 2018;37:1347-50.

48. Ang M, Mehta JS, Newman SD, et al. Descemet membrane endothelial keratoplasty: preliminary results of a donor insertion pull-through technique using a donor mat device. Am J Ophthalmol. 2016;171:27-34.

49. Busin M, Leon P, D'Angelo S, et al. Clinical outcomes of preloaded Descemet membrane endothelial keratoplasty grafts with endothelium tri-folded inwards. Am J Ophthalmol. 2018;193:106-13.

50. Leon P, Parekh M, Nahum Y, et al. Factors associated with early graft detachment in primary Descemet membrane endothelial keratoplasty. Am J Ophthalmol. 2018;187:117-24.

51. Price MO, Lisek M, Kelley M, et al. Endothelium-in versus endothelium-out insertion with Descemet membrane endothelia keratoplasty. Cornea. 2018;37:1098-101.

52. Ong HS, Ang M, Mehta JS. Endothelium-out and endotheliumIn Descemet's membrane endothelial keratoplasty (DMEK) graft insertion techniques: a systematic review.(Preliminary unpublished data, under review).

53. Barnes K, Chiang E, Chen C, et al. Comparison of tri-folded and scroll-based graft viability in preloaded Descemet membrane endothelial keratoplasty. Cornea. 2019;38:392-6.

54. Romano V, Ruzza A, Kaye S, Parekh M. Pull-through technique for delivery of a larger diameter DMEK graft using endothelium-in method. Can J Ophthalmol. 2017:52:e155-6.

55. Parekh M, Ruzza A, Ferrari S, et al. Endothelium-in versus endothelium-out for Descemet membrane endothelial keratoplasty graft preparation and implantation. Acta Ophthalmo 2017;95:194-8. 